\title{
5. Mixing Modes to Widen Research Participation
}

\section{Jo Hope}

In this chapter I discuss mixing online and offline modes as a means to diversify participation in social research. While Orgad (2009) has discussed adding offline to online modes, I focus on adding digital methods to an offline methodology, arguing that traditional modes of research can make it difficult for some people to participate, leading to potential sample biases.

I use a case study from my own research to illustrate key considerations when using mixed modes. These are reflected in the organisation of the chapter, which explores mixed mode recruitment, preparing to use mixed modes and assessing the impact of mixing modes. I argue that if comparability of data is planned into the design, differences between modes can be minimised and the quality of data enriched through wider participation. I conclude the chapter with a set of recommendations for how other researchers might fruitfully use a mixed-mode approach.

\section{Background}

There are debates about the nature, quality and comparability of data collected across different modes. Survey researchers have tended to take a pragmatic approach to combining web and mail surveys (Dillman et al., 2009a), while the legitimacy of online interviews can be contentious. There are concerns that email interview responses, which can be edited before sending, mask the hesitation 
FINAL DRAFT ACCEPTED FOR PUBLICATION, PAGINATION DIFFERS.

and repairs evident in verbal interviews (Kazmer and Xie, 2008). Others argue that a lack of embodied cues can make it harder to interpret email communication (e.g. Markham, 2004). Possible limitations of Voice over Internet Protocol (VoIP) interviews include 'drop outs' of video and audio, relatively higher attrition (Deakin and Wakefield, 2013) and a need for interviewer and interviewee to have relevant technical skills and feel comfortable on camera (Hay-Gibson, 2009). If such issues are common they could impact on the quality of online interview data in terms of a greater social desirability bias, lower levels of rapport, poorer in-interview interpretation and recruitment biases, which would affect its comparability with offline data.

The case study presented below aimed to increase the diversity of participation by avoiding the inadvertent exclusion of some groups through the exclusive use of offline modes of data collection and recruitment. A brief outline of the research aims and design is given below to provide a context for the rest of the chapter.

\section{Research aims and design}

The case study presented here is my research into the role of online support and information in the caring practices of parents of people with a rare syndrome (Rett syndrome). Rett syndrome is associated with disability and severe and unpredictable health problems (Smeets, Pelc and Dan, 2011). It is thought to affect about 2,500 females in the United Kingdom (Neurological Alliance, 2003) with a much lower prevalence among males (Kerr, 2002). I was interested in whether online peer support use was socially differentiated, if it was used for inequitable gains, and how it connected to everyday caring practices. As I aimed to explore both social patterning and individual experiences, a mixed methods approach was used. The first stage involved completion of a choice of paper or online survey by parents of people with Rett syndrome living in the United Kingdom. This focused on use of and attitudes towards the Internet and online support and key demographic information. The second stage involved mixedmode, semi-structured interviews with parents of people with Rett syndrome who had used online support within the last three years. A choice was given 
FINAL DRAFT ACCEPTED FOR PUBLICATION, PAGINATION DIFFERS.

initially between face-to-face, telephone and VoIP interviews, with email interviews offered if other modes were unsuitable. Eligible interviewees were recruited through the survey (and later through the online channels described below). The interview focused on the role of peer online support sources in wider information-seeking and caring practices.

\section{Mixed-mode recruitment}

Like many other social researchers, I was interested in recruiting a diverse sample from a hidden population with no comprehensive sampling frame. For the survey stage, I aimed to recruit parents from a range of social backgrounds, with differing experiences of the Internet and online peer support. As the survey provided screening for the interviews, it was important to recruit current users of online peer support. In this section, I describe how online recruitment aided me in reaching a more diverse group of eligible parents.

At the time of my research there were three charities with different focuses: Rett UK, which aimed to provide support to carers (established in 1985), The Rett Syndrome Research Trust, which focused on genetic therapy and treatment research (established in 2009) and Cure Rett (established 2012), which aimed to provide support and to fund research. Rett UK's membership database was the largest, most up-to-date list of relatives of people with Rett syndrome available in the United Kingdom ( $n=619 ; 555$ of whom were identifiable as parent members). Contacts at the Rett Syndrome Research Trust and Cure Rett advised me that the best way to recruit parents interested in their work was through their Facebook Pages. However, as diversity of sample was crucial, I used additional recruitment channels.

It has been argued that online support and discussion groups can provide (in this case, widened) access to hidden groups, particularly those sharing a narrowly defined interest, such as a specific illness (Hesse-Biber and Griffin, 2012). Through online searches and consultation with Rett UK members, I 
discovered a range of Rett syndrome-specific and broader carers' support sites, groups and email lists. However, these sites and groups did not collect or provide enough information to allow me to create a larger sampling frame based on my eligibility criteria. It was therefore not possible to estimate how many parents would see research requests (especially on public pages), or to avoid some parents receiving multiple invitations to participate. This, along with the relatively small Rett UK sample, meant I could not carry out a randomised sample, so instead sampled for diversity. I used this data as a background to relate qualitative findings to social patterning in the survey population without claiming generalizability to the whole population.

I sent personalised letters to all parent and unidentified family members in the Rett UK database in November 2012. These included a paper survey and provided a link to the online survey, so members could choose their preferred response mode. An invitation to participate was also included in Rett UK's paper newsletter, which was sent to all members (including parents, other family members, professionals and others with an interest in Rett syndrome).

I opened research-specific accounts on Facebook, Twitter and Carers UK's online forums to allow me to communicate with others on these sites. I also created a website ${ }^{1}$, allowing me to overcome the limits of recruiting on sites requiring brevity (such as Twitter). My site was linked to my University of Surrey web page and included my email address so parents could authenticate my identity. Relevant online gatekeepers were approached to gain permission for me to post recruitment notices directly or (if they preferred), for them to post on my behalf. I posted on online forums at different times of day to gain a wide audience but concentrated on Friday evenings, so my post was displayed at a popular time when more people would see it (Saturday morning).

A follow-up letter was sent to family members on the Rett UK database in early 2013 with a link to the online survey and a form for requesting a new survey or providing information about non-response. A final reminder was also included in Rett UK's paper newsletter. Reminder posts were shared through all online channels used previously, along with requests for interviewees. The two

\footnotetext{
${ }^{1}$ See http://rettonlinesupport.wordpress.com/
} 
FINAL DRAFT ACCEPTED FOR PUBLICATION, PAGINATION DIFFERS.

interviewees through online channels also completed surveys before completing the interview.

\section{Preparing to use mixed modes}

This section explores my methodological reasons for choosing mixed modes and how they can be designed to foster comparability. As outlined above, my aim was to encourage participation by a diverse group of parents. By providing a choice of ways to participate, I hoped to avoid inadvertently excluding participants who were unable to participate in a particular mode. As access to and use of the Internet remains socially differentiated (e.g. see Dutton and Blank, 2013), the exclusive use of online methods will exclude some people. However, as argued below, the exclusive use of offline methods may exclude other people.

\section{Mixed-mode surveys}

For people can touch-type and have access to the Internet in a number of contexts, an online survey may be quicker and easier to complete than a paper version. However online and offline survey modes can differ, causing mode effects, which can be somewhat ameliorated by standardizing question format and presentation across modes (Dillman and colleagues, 2009a). I therefore created my survey in SurveyMonkey (an online web survey site) and downloaded a PDF version to use as my paper survey. However, some factors that led to unavoidable differences between modes, outlined below.

In all paper surveys posted to Rett UK members, I excluded a question about channel of recruitment that was included in the online survey, to avoid disengaging respondents. Similarly, I excluded a question from the web survey about current Internet access as completing a web survey demonstrated access.

There were also some unavoidable experiential differences between modes. First, although I tried to ensure parity between pages by mode, they would format differently on different web devices. Second, respondents were redirected automatically online at key decision questions, but given directions to 
FINAL DRAFT ACCEPTED FOR PUBLICATION, PAGINATION DIFFERS.

skip questions in the paper survey. This increased the reading burden on paper survey respondents and allowed the completion of irrelevant questions on the paper but not the online survey. As it transpired, however, the 'correct' decision in paper surveys was clear from subsequent answers, which made this less problematic. Finally, I avoided the online survey 'forcing' people to respond to questions before completing a page so they could skip questions as freely as on the paper survey. However I could not do this for key decision questions without losing the automatic redirection function.

\section{Mixed-mode interviews}

I chose mixed mode interviews because I was concerned that a synchronous face-to-face interview may be inappropriate for some potential participants. Like many other researchers, my group of interest included people with unpredictable schedules, who worked long hours or had other competing demands on their time. I was keen to avoid excluding parents of children with the most severe health problems and fulltime workers whose children lived at home. I also wished to avoid geographical mode effects, particularly a bias toward face-to-face interviews in my local region. Finally I hoped that having a choice would prompt interviewees to choose the most convenient and comfortable mode, which might aid rapport and disclosure.

To support the comparability of interview modes, each was based on the same semi-structured schedule. I tried to make the email interview as like other modes as possible by preserving a conversational element, presenting a few questions at a time and responding flexibly depending upon responses where possible. Fifty eligible parents indicated an interest in participating. At initial research contacts (by email with follow-up by phone), parents were advised that interviews were expected to take between one and a half to two hours. A choice was given between three synchronous modes: face-to-face, VoIP interviews and telephone interviews, with email interviews offered as an alternative if none were suitable. However, I stressed that the content of email interviews would be the same as in synchronous interviews. 


\section{Assessing the impact of mixing modes on participation}

I carried out a series of tests on demographic mode differences to assess the impact on participation. This section describes my results and can be used as a worked example of how impact could be assessed by other researchers. Although my sample was not randomly selected and not generalizable, I used statistical tests because they are less subjective than judgments based on descriptive statistics (Sapsford, 2007, p.90). These results thus demonstrate the strength rather than the generalizability of my findings.

\section{Recruitment from different modes}

A total of 190 surveys were received from eligible parents. Given the lack of a comprehensive sampling frame, overall response rate was difficult to assess. There was a 26 per cent response rate $(n=158)$ from the letter recruitment frame. However, a probable overestimation of eligibility means the response rate may have been higher. For instance, some parents contacted me to say their child had had their diagnosis changed by health professionals, and there was limited information about 64 relatives on the mailing list, who may not have been parents.

I discovered later that providing people with a choice of mode when their preference is not known has been found to reduce response rate by around one to nine per cent (see Dillman, Christian and Smyth, 2009 for a summary). I was not aware of this finding at the time of recruitment and it is possible my approach may have slightly reduced the response rate.

To assess the impact of recruitment mode on participation, I compared respondents recruited solely through online sources with those reached through at least one offline channel (sometimes in addition to online channels). This meant I could compare respondents only reached online with all others. Overall, 22 respondents -12 per cent of my sample - were recruited solely through an online source. The online-only recruits had a younger mean age (41 years old, ranging from 23 to 60 years old) than the other group (52 years old, ranging from 29 to 89 years old). A chi-square comparison of age groups was significant, 
$\chi^{\text {回 }}(4)=28.30 p \leq .001$, with a significant and moderate association between age and recruitment mode (Cramer's V score of .393, p <.001). The significance derived mostly from the much higher percentage of the 23-34 year age group $(\mathrm{p}<$ .001) that were reached only online. Thirty-four per cent of this group were recruited solely online compared to the sample average of 8 per cent. The use of online recruitment more than doubled the number in this age group from 7 to 15. There were no statistically significant differences found in chi-square tests comparing household income and education levels between these groups. However, an error introduced during the printing process meant the bottom three household income groups could not be differentiated in the paper surveys, so had to be coded together as 'below $£ 30,000$ '. This may have masked any differences associated with the lowest household income values.

\section{Factors connected to survey mode choice}

I carried out similar comparisons to explore survey mode choice. No significant differences were found in terms of educational level, household income (but see above) and use of mobile Internet devices. Instead mode choice was partly connected to mode of recruitment and to age. Seventy-three per cent of those recruited by letter returned a paper survey while none of the respondents recruited through online channels requested one.

Those who chose an online survey were significantly younger on average than those choosing a paper survey ${ }^{2}$ This partly reflects the overlap between data collection mode with recruitment mode because when letter-recruited parents only were tested, the median age of web survey respondent increased to 48.3 years old while the median age of paper survey respondents remained the same. This difference remained significant, although its strength reduced ${ }^{3}$. This

\footnotetext{
2 Online survey respondents had a median age of 45.4 years, while paper survey respondents had a median age of 54.4 years old, a significant difference, $U=$ $2633, z=-3.99, p<.001, r=-.29$. These results suggest that age difference accounted for about 29 per cent of the differences found in choice between survey modes.

${ }^{3} U=1745.5, z=-2.40, p<.05, \mathrm{r}=-.19$. These results suggest that about 20 per cent of differences in survey choice among letter-recruited parents could be explained by age.
} 
supports the suggestion that including an online mode had a separate effect in increasing uptake among younger parents. These findings flag the possibility that mode effects may be confounded with age differences, which is examined in the section on assessing the impact of mixing modes.

Self-rated ability to use the Internet may also have played a part in mode choice. The single person who rated their ability to use the Internet as 'bad' and two of the three who rated it as 'poor' completed a paper survey. Of those who rated their ability to use the Internet as 'good' or 'excellent', 53.9 per cent chose to complete a paper survey. This suggests that once a certain level of online competence is achieved, mode convenience is important but below that, there may not be genuine 'choice' between modes.

\section{Factors connected to interview mode choice}

Just under half of interviews ( $n=9$, including a joint interview with a couple) were undertaken face-to-face, with the rest carried out over the phone $(n=5)$, VoIP call $(n=3)$ and email $(n=3)$.

Table 5.1 presents key demographic characteristics of interviewees. Age was again an important factor, with all interviewees aged over 54 choosing a face-to-face interview over other modes. As hoped, there was not a strong geographical mode bias. Interviews in my region (the South East) were carried out in all modes and over half of my interviews were with parents living outside my region. However none of the interviews in the North West were carried out in person. In part this was due to parents' concerns about my travelling a long way to interview them, which was sometimes compounded by interviewees' doubts about the relevance of their experience. This was particularly true for parents who saw themselves as not using online support 'enough'. I tried to counteract this by reassuring all interviewees of the importance of their account and, where possible, combining travel to interviews with some other research activity. 
FINAL DRAFT ACCEPTED FOR PUBLICATION, PAGINATION DIFFERS.

Table 5.1 Interviewee demographic and socioeconomic details by mode

\begin{tabular}{|c|c|c|c|c|}
\hline & $\begin{array}{l}\text { Face-to-face } \\
(n=9)\end{array}$ & $\begin{array}{l}\text { Telephone } \\
(n=5)\end{array}$ & $\begin{array}{l}\text { VolP } \\
(n=3)\end{array}$ & $\begin{array}{l}\text { Email } \\
(n=3)\end{array}$ \\
\hline \multicolumn{5}{|l|}{ Gender } \\
\hline Female & 8 & 5 & 2 & 1 \\
\hline Male & 1 & 0 & 1 & 2 \\
\hline \multicolumn{5}{|l|}{ Age } \\
\hline $23-34$ & 0 & 1 & 0 & 0 \\
\hline $35-44$ & 4 & 1 & 1 & 3 \\
\hline $45-54$ & 1 & 3 & 2 & 0 \\
\hline $55-64$ & 3 & 0 & 0 & 0 \\
\hline \multicolumn{5}{|l|}{ Region resident } \\
\hline North West & 0 & 3 & 0 & 1 \\
\hline South West & 2 & 0 & 0 & 0 \\
\hline South East & 3 & 1 & 1 & 2 \\
\hline London & 2 & 0 & 0 & 0 \\
\hline East of England & 0 & 1 & 0 & 0 \\
\hline Yorkshire and the Humber & 2 & 0 & 1 & 0 \\
\hline (United Arab Emirates) & 0 & 0 & 1 & 0 \\
\hline \multicolumn{5}{|l|}{ Occupational status } \\
\hline Working fulltime & 1 & 4 & 2 & 1 \\
\hline Working part-time & 3 & 0 & 1 & 1 \\
\hline Unemployed & 0 & 0 & 0 & 1 \\
\hline $\begin{array}{l}\text { Doing housework, looking after children } \\
\text { or other persons }\end{array}$ & 4 & 1 & 0 & 0 \\
\hline \multicolumn{5}{|l|}{$\begin{array}{l}\text { Occupation groups of working } \\
\text { interviewees }\end{array}$} \\
\hline Managers, Directors and Senior Officials & 0 & 2 & 2 & 1 \\
\hline Professional Occupations & 3 & 1 & 0 & 1 \\
\hline Associate Professional and Technical & & & & \\
\hline Occupations & 2 & 1 & 0 & 0 \\
\hline Caring, Leisure and Other Service & & & & \\
\hline Occupations & 0 & 0 & 1 & 0 \\
\hline
\end{tabular}

Confidence in ability to contribute to research is therefore a potential bias that could affect recruitment to single mode face-to-face interviews, even when the interviewer is able to travel widely. One man from the United Arab Emirates participated in the interview. Basic screening did not pick this up earlier as he had previously lived in the UK for one year as a Masters student. However, I 
FINAL DRAFT ACCEPTED FOR PUBLICATION, PAGINATION DIFFERS.

agreed to interview him as it added interesting data about the use of UK online support by a foreign national.

Occupational status also appeared to play a part in participation in interviews, but household income alone did not seem to have an impact (but see earlier problems with this measure). All but one of the full-time carers chose face-to-face interviews (one carer from the East of England chose a telephone interview). All except one parent who worked full-time (who was a freelancer), chose modes of interview that were not face-to-face. No interviewees working at the most senior level participated in a face-to-face interview. This could reflect the additional time burden of a face-to-face interview, which requires a longer 'lead-in' time (such as finding a suitable room, setting up equipment and being offered a cup of tea) than more time-bounded Skype or telephone interviews or asynchronous email interviews.

None of the four men who participated chose a face-to-face interview on his own. One man participated in an interview alongside his wife and the other three men choose online-mediated modes (two email and one VoIP). One male interviewee chose email because it fitted into his working day while an (unemployed) male interviewee chose email as a communication preference: "I personally feel that I write better than I speak/converse."

Google Hangouts (a VoIP) was used by one male interviewee in a way that suggested a cultural element to what Hanna (2012) calls the "neutral yet personal" space of a Skype interview, which offers comfort without intrusion:

I am an Arab, I am a Muslim [...] Okay, erm [...] in fact the reason that I delayed my interview with you two weeks ago if you remember...[was] in fact to have interview with my, with my family around me... because I don't feel comfortable when I talk [...] to a woman while I am alone.

Here then the presence of the family on one side of the screen (in a different room) with the interviewee on the other meant he was able to participate in a one-to-one interview with a female interviewer. 
FINAL DRAFT ACCEPTED FOR PUBLICATION, PAGINATION DIFFERS.

Table 5.2 shows how mode choice differed by online competence and use of the Internet at work. Those who chose a VoIP interview all rated their ability to use the Internet as 'excellent' and used it at work. This did not hold for email interviews, which may be due to the ubiquitous diffusion of email use in the UK, which stands at 97 per cent, while only 45 per cent use VoIP software (Dutton and Blank, 2013). Conversely almost all interviewees who rated themselves as 'good' rather than 'excellent' users of the Internet chose an offline form of interview, while among more confident and experienced Internet users a range of modes were used. Length of time using the Internet may also have been important, with the person using the Internet for the least time (six years) choosing an offline mode. Overall, this echoes the survey finding in that a certain level of competence appears necessary to allow a genuine 'choice' between modes.

In summary, adding online recruitment and online data collection modes led to a greater inclusion of younger parents, working parents, geographicallydistant parents and men, but VoIP use may have been limited to the most confident Internet users.

Table 5.2 Internet expertise and confidence by mode of interview

\begin{tabular}{|c|c|c|c|c|}
\hline & $\begin{array}{l}\text { Face-to-face } \\
(n=9)\end{array}$ & $\begin{array}{l}\text { Telephone } \\
(n=5)\end{array}$ & $\begin{array}{l}\text { VolP } \\
(n=3)\end{array}$ & $\begin{array}{l}\text { Email } \\
(n=3)\end{array}$ \\
\hline \multicolumn{5}{|c|}{ Years using Internet } \\
\hline $0-5$ years & 0 & 1 & 0 & 0 \\
\hline $6-10$ years & 3 & 4 & 1 & 1 \\
\hline $11-15$ years & 5 & 0 & 2 & 1 \\
\hline $16-20$ years & 0 & 0 & 0 & 1 \\
\hline \multicolumn{5}{|c|}{$\begin{array}{l}\text { Self-rated ability to } \\
\text { use the Internet }\end{array}$} \\
\hline Good & 3 & 2 & 0 & 1 \\
\hline Excellent & 5 & 3 & 3 & 2 \\
\hline \multicolumn{5}{|c|}{$\begin{array}{l}\text { Uses the Internet at } \\
\text { work }\end{array}$} \\
\hline Yes & 3 & 4 & 3 & 2 \\
\hline No & 5 & 1 & 0 & 1 \\
\hline
\end{tabular}




\section{Assessing the impact of mixing modes}

This section demonstrates how mixed mode data can be examined to test crossmode comparability.

\section{Assessing mode effects in survey responses}

In mixed mode survey research a key concern is measurement error: differences in how questions are answered in each mode. It can be difficult to disentangle mode effects from subgroup effects (Dillman, Christian and Smyth, 2009a) when certain subgroups are overrepresented in a particular mode, as here. However, some recent research comparing mode effects between mail and web surveys found no significant differences in terms of the choice of more extreme categories on rating scales or on missing item counts (Dillman et al., 2009b; Börkan, 2010). Börkan (2010) argues that where web and mail mode effects have been found, these were in studies not specifically designed to compare mode effects.

My own data supported these findings as there was no evidence of one group scoring more strongly on both ends of the scale on a common attitude question (about confidence in health professionals) and the mean response was very similar (paper was 4.0 and online was 3.8). I also split the data by age groups to compare differences in the same question by mode and found no evidence of extreme responses at both ends. Similarly, there was no significant difference between the mean percentage of missing data in paper surveys (3.3 per cent) and online surveys (4.3 per cent). This suggests there were no mode effects masked by subgroup differences in age. This was however difficult to interpret as in higher age groups there were smaller numbers of respondents, so percentages could be misleading. 
FINAL DRAFT ACCEPTED FOR PUBLICATION, PAGINATION DIFFERS.

It has been suggested that open response boxes are used differently online, with digits used instead of alphanumeric numbers, which affects character count (Fuchs, 2009). Written text may also vary in size in a way that typed text in survey software does not. I therefore tested for mode effects in the completion of a further information comments box at the end of the survey. The proportion of respondents completing this box was similar and not significantly different (26.7 per cent on the paper and 23 per cent on the web survey). The mean number of words used was virtually identical (12.2 for paper, 12.5 for online) and characters (without spaces) were very close, 55.7 on paper and 56.5 online. Neither comparison significantly different. However, ten respondents used margins in the paper survey to embellish answers to closed questions, which was not possible in the web survey, although similar clarifications were included in open response boxes online.

In summary there were no significant differences between modes in terms of measurement error as it was tested here. This suggests that the web and paper survey data were similar in terms of responses, meaning all data could be combined without serious concerns about comparability.

\section{Assessing mode effects in online interviews}

To assess the mode effects in online interviews, I focused on addressing concerns in the literature related to research process, technical problems, establishing rapport and the expression of emotion.

The attrition in email interviews differed from other modes. Three parents did not initially respond to the first interview email after giving consent (one parent did not respond to follow-up contacts, one withdrew due to time commitments and the third withdrew because her daughter was in intensive care). However, when other parents changed their minds about participating in other modes of interviews, they informed me first. This may reflect differences in expectations between synchronous and asynchronous modes of communication, where a response to an email can be postponed or, at times of difficulty, ignored.

Two of the three email interviews were completed. Following a long email silence I managed to re-establish contact with the other interviewee who told me 
they had experienced a mental breakdown, that an email interview was too pressured and requested a face-to-face or telephone interview. We agreed to terminate the interview altogether after a mutually agreed delay and they agreed to allow me to use their existing data.

These experiences highlight the difficulties of using email interviews with people with unpredictable schedules, whose situations may change either before or during the interview. It also highlights that for some members of this group, an email interview, though episodic, may represent a greater felt commitment of time.

Skype presented particular, but not usually insurmountable, technical challenges. After problems with unclear audio, one Skype interview had to be transferred to a telephone interview. In all other cases, connections on both sides of the interview were good enough for it to go ahead. Audio glitches during the interview were infrequent. When they did occur they were dealt with during the interview, with questions or answers repeated on request.

The other element of Skype that made it different from a face-to-face interview was eye contact. I developed a technique to mimic eye contact by moving the video window of the interviewee to just below my webcam, but it was disconcerting not to have a similar experience of eye contact from the interviewee. However, like Deakin and Wakefield (2014), I did not experience any difficulties developing rapport when interviewing over VoIP.

Humour was important across all modes of interviews, both in terms of reducing tension and increasing rapport. This was expressed in terms of laughter in the verbal interviews (including over VoIP) and included jokes made by interviewees in both completed email interviews (indicated by a smiley emoticon: ()).

Similarly, some parents in each mode discussed sensitive topics relating to their emotional response to their child's diagnosis, with one parent moved to tears during a VoIP interview. In email interviews parents conveyed emotion through the use of exclamation marks (as described by Kazmer and Xie, 2008) but also through descriptions of emotional states and quotation marks.

Two email interviews also felt relatively spontaneous in tone. These were both carried out on work accounts (both parents reassured me they were happy 
to do so). Both had a conversational quality at odds with the carefully crafted and constructed email responses described by James and Busher (2009), while one carried out on a personal account could be stilted, with short responses, although stronger rapport, with more embellished answers, was eventually established. This may be due to a potentially greater use of email by both working interviewees, who had mobile and work access to the Internet, while the other interviewee did not. The following excerpt from one of the work email interviews demonstrates the expression of emotion, while the volume of words and uncorrected spelling mistake towards the end suggest a certain level of unselfconscious spontaneity. The text is in response to a question about the interviewee's experience of receiving her daughter's diagnosis.

Catherine: Appalling to say the least. Ellen's community paed refused for a long time to actually voice her opinion on what she thought was wrong with Ellen, kept saying delayed development!!! When me and her Dad refused to leave her office until she told us what she 'thought' it was, she then said that she thought it was Rett Syndrome which of course meant nothing to us. She then said she had sent a blood sample from Ellen to GOSH for testing (no permission from us to do this!) and that in the meantime we should go home and look up RS on the internet!!! [...] [After the diagnosis there was] still no further support, so I then called GOSH who were great and we went there the next day to see a genetist who told us the science bit and hooked us up with a doctor specialising in RS, I also contacted Rett UK, we then had more support. Still makes me very angry today!

Other than the higher dropout rate in email interviews, the only other difficulty was a lack of telling pauses and retractions. These were present in other interviews when parents began to talk about contentious topics such as the role of perceived class differences in befriending other parents. VoIP interviews were very similar to face-to-face interviews except for the occasional technical problem. Overall then online interviews could be equivalent to offline interviews 
FINAL DRAFT ACCEPTED FOR PUBLICATION, PAGINATION DIFFERS.

in eliciting detailed accounts, allowing emotional expression, building rapport, aiding disclosure and attaining - for habitual email users at least - some level of spontaneity.

\section{Conclusion and recommendations}

My aim in using mixed mode recruitment and data collection was to widen participation. Mixed mode recruitment was successful in allowing me to access a wider age range of parents than via a single mode. Similarly, adding online modes encouraged the participation of a wider range of parents, including those who worked full time and geographically distant parents. Significantly, online methods seemed to be more attractive to male participants, who can be underrepresented in survey research (O'Rourke and Lakner, 1989), and research on sensitive topics (e.g. Lloyd, 1996). Attempts to make data collection modes as equivalent as possible may have contributed to a lack of mode effects found in tests on the survey data. It was possible to build rapport in all interview modes, demonstrated by interviewees' ability to express emotion, use humour and disclose about sensitive experiences within each mode. While email interviews could be disrupted by changes in circumstances and could be perceived as a heavier commitment, they enabled some parents to participate who were unwilling or unable to participate in other modes. They could also be spontaneous and unedited, particularly when used by people with greater access to the Internet, although telling pauses and retractions were absent. Similarly, while VoIP interviews could be disrupted by technical problems, they allowed wider participation among the most confident net users and shared many aspects of face-to-face interviews.

I conclude this chapter with the following recommendations for researchers considering combining online and offline modes: 
FINAL DRAFT ACCEPTED FOR PUBLICATION, PAGINATION DIFFERS.

- Mixed mode recruitment should be considered when sampling for diversity, but not generalizability, among a hidden population.

- Offline, as well as online, modes of data collection should be offered when carrying out research in a population where not all members are very confident Internet users.

- The use of online data collection should be considered when trying to recruit men to studies, particularly those with sensitive topics.

- When mixing modes, steps should be taken to provide as similar a research experience as possible across modes.

- When combining online and offline surveys:

○ different modes should be offered consecutively, for example paper surveys sent with a first letter - with a link to the online mode provided at follow-up;

- mode effects should be investigated before data is combined.

- A choice of interview modes should be offered to avoid geographical biases in interview mode, if feasible.

- Consider offering alternatives to face-to-face interviews for groups with heavy time constraints or unpredictable schedules.

- Differences in the research process across modes that may affect rapport or data quality should be explored and discussed when reporting findings.

\section{References}

Börkan, B. (2010). The Mode Effect in Mixed-Mode Surveys: Mail and Web Surveys. Social Science Computer Review, 28(3), 371-380.

Deakin, H., and Wakefield, K. (2013). Skype interviewing: Reflections of two PhD researchers. Qualitative Research. doi: 10.1177/1468794113488126. Retrieved August 19, 2014, from http://qrj.sagepub.com/cgi/doi/10.1177/1468794113488126 
FINAL DRAFT ACCEPTED FOR PUBLICATION, PAGINATION DIFFERS.

Dillman, D., Christian, L. and Smyth, J. (2009). Internet, mail and mixed-mode surveys: the tailored design method, $3^{\text {rd }}$ Edition. Hoboken, New Jersey: Wiley.

Dillman, D., Phelps, G., Tortora, R., Swift, K., Kohrell, J., Berck, J., and Messer, B.L. (2009). Response rate and measurement differences in mixed-mode surveys using mail, telephone, interactive voice response (IVR) and the Internet. Social Science Research, 38(1), 1-18.

Dutton, W.H., and Blank, G. with Groselj, D. (2013). Cultures of the Internet: The Internet in Britain. Oxford Internet Survey 2013. Available at: http://oxis.oii.ox.ac.uk

Fuchs, M. (2009). Differences in the Visual Design Language of Paper-and-Pencil Surveys Versus Web Surveys: A Field Experimental Study on the Length of Response Fields in Open-Ended Frequency Questions. Social Science Computer Review, 27(2), 213-227.

Hanna, P. (2012). Using internet technologies (such as Skype) as a research medium: a research note. Qualitative Research, 12(2), 239-242.

Hay-Gibson, N.V. (2009). Interviews via VoIP: Benefits and Disadvantages within a PhD study of SMEs. Library and Information Research, 33(105), 39-50.

Hesse-Biber, S., and Griffin, A.J. (2012). Internet-Mediated Technologies and Mixed Methods Research: Problems and Prospects. Journal of Mixed Methods Research, 7(1), 43-61.

James, N., and Busher, H. (2009). Online Interviewing. London: Sage.

Kazmer, M., and Xie, B. (2008). Qualitative Interviewing in Internet Studies: Playing with the media, playing with the method. Information, Communication and Society, 11(2), 257-278. 
FINAL DRAFT ACCEPTED FOR PUBLICATION, PAGINATION DIFFERS.

Kerr, A.M. (2002). 'Annotation: Rett syndrome: Recent progress and implications for research and clinical practice', Journal of Child Psychology and Psychiatry, 43(3), 277-87.

Lloyd, M. (1996). Condemned to be meaningful: Non-response in studies of men and infertility. Sociology of Health and Illness, 18(4), 433-454.

Markham, A.N. (2004). The Internet as Research Context. In C. Seale, G. Gobo, J.F. Gubrium, \& D. Silverman (Eds.), Qualitative Research Practice (pp. 328-345). London: Sage.

Orgad, S. (2009). How can researchers make sense of the issues involved in collecting and interpreting online and offline data? In Markham, A., and Baym, N. (eds.) Internet inquiry: conversations about method. Thousand Oaks, CA: Sage.

O'Rourke, D. and Lakner, E. (1989). Gender bias: analysis of factors causing male underrepresentation in surveys. International Journal of Public Opinion Research, 1(2), 164-176.

Sapsford, R. (2007). Survey Research, $2^{\text {nd }}$ Edition. London: Sage.

Smeets, E., Pelc, K., and Dan, B. (2011). Rett Syndrome. Molecular Syndromology, $2,113-127$. 